\title{
Whole Body Vibration: A Revolutionary Mode of Exercise or A Trend?
}

\section{Vassilis Gerodimos}

Department of Physical Education and Sport Sciences, University of Thessaly, Karies, 42100 Trikala, Greece

Whole-body vibration (WBV) has received a lot of attention as an effective exercise modality in sports and rehabilitation settings during the last decades $[1,2]$. Many health centres promoted WBV exercise as an innovative mode of exercise that requires less volitional input and may replace traditional resistance exercise. More specifically, WBV exercise has gained popularity as an alternative less fatiguing and less time-consuming mode of exercise for improving different features of physical fitness and health. WBV has also been marketed, by many companies, as a suitable weight-loss and body toning workout, demonstrating that $10 \mathrm{~min}$ of WBV exercise is equal to $1 \mathrm{~h}$ of traditional resistance exercise [3]. However, the important question is: 'Has WBV exercise the ability to improve various indices of health, overall fitness and functional capacity, as previously purported by the lay literature?'

WBV is a mechanical stimulus characterized by oscillatory motion [1]. During WBV exercise, mechanical stimuli are transferred from the feet to the rest of the body by use of vibrating platforms $[2,4]$. The potential mechanisms that might explain the possible beneficial effects of WBV on neuromuscular performance comprise hormonal factors, the activation of the "tonic vibration reflex", and alterations in proprioceptors discharge [5]. The WBV loading parameters include frequency (the repetition rate of the cycles of oscillation, in $\mathrm{Hz}$ ), amplitude (the extent of the oscillatory motion, in $\mathrm{mm}$ ) and duration [1]. The interaction of frequency and amplitude determine the WBV acceleration (in $\mathrm{m} / \mathrm{s}^{2}$ ), and their different combinations determine the training load $[6,7]$.

The effects of WBV training on fitness parameters are influenced by the subject's characteristics (age, gender, training and health status) and by the vibration training characteristics (e.g. vibration frequency and amplitude, duration, training frequency, body position) [8]. An additional important factor that could influence the efficacy of WBV exercise on the human body is the mode of vibration (vertical simultaneous vs. side to side alternating movement) [8]. Indeed, there is evidence that side-to-side WBV platforms: a) may induce a different degree of muscle stretch and tissue vibration in leg muscles leading to different neuromuscular adaptations [9], b) evoke greater heart rate responses [10] and c) transfer less mechanical energy to the head and neck of the human body in relation to vertical simultaneous platforms [9], and thus, are considered safer for untrained individuals as well as for individuals with chronic diseases.

It should be mentioned that WBV may provoke harmful effects on the human body when is used inappropriately [2]. The attitudes concerning the appropriate use of WBV exercise in healthy and clinical populations are divergent. Although, WBV is not recommended as an efficient training modality in people with acute inflammation as well as with acute cardiovascular and musculoskeletal conditions; however, its therapeutic use on the aforementioned diseases has been previously reported $[2,11]$. More specifically, recent studies have reported that WBV is a beneficial exercise modality for neurological, musculoskeletal and metabolic patients[2,12].

Taking all the above into consideration, research has been lately (the last 5-6 years) focusing on the efficacy of different WBV training programs so as to find the safest and effective exercise training regime. Thus, several studies have investigated either the acute (following one

\section{Publication History:}

Received: December 23, 2015

Accepted: December 30, 2015

Published: December 31, 2015

\section{Keywords:}

Vibration training, Mechanical stimulus, Physical fitness, Health, Rehabilitation

session of WBV exercise) or the chronic effects of WBV training in different systems of the human body such as cardiovascular, musculoskeletal, endocrine, nervous etc.

\section{Acute effects of whole-body vibration exercise}

The acute effects of WBV on different features of physical fitness and health are not clear. An acute bout of WBV using either side-to-side alternating or vertical simultaneous vibrations have shown to increase [13-15] or not change [16-18] vertical jumping ability, strength and/ or balance. However, a $9.1 \%$ reduction in counter movement jump and/or strength has also been reported after exhaustive or prolonged WBV exercise [19]. The equivocal findings among studies may be due to the characteristics of WBV protocols, such as the training methods, the loading parameters, the body positions, and the mode of vibration. Although the results regarding power, strength and balance seem to be opposing, the vast majority of studies that investigated the acute effects of WBV exercise on flexibility documented significant improvement (by 8.2-16.2\%) [16]. Additionally, an acute bout of WBV may: a) increase vasodilatation of vibrating muscles, cutaneous and deep vessel blood flow and muscle temperature, b) increase heart rate and c) reduce tissue viscosity and increase muscle elasticity [20]. Thus, WBV is recommended by many investigators as an alternative warm-up training routine. There is also evidence that a single bout of WBV may be a more efficient warm-up method compared to traditional methods, such as stretching, that may decrease strength and power. Finally, other studies that investigated the acute effects of WBV exercise on biochemical indices have also reported inconsistent findings. In detail, an acute WBV bout was found to reduce plasma iterleukin-6 and muscle soreness after downhill running [21], as well as to increase plasma free fatty acids [22] and decrease plasma glucose concentration [23]. While previous study did not report any acute effect of WBV exercise on muscle and liver damage as well as on systemic inflammation [24].

\section{Chronic effects of whole-body vibration training}

Previous studies that examined the effects of a chronic WBVT program consisting solely of WBV on neuromuscular performance "Corresponding Author: Vassilis Gerodimos, Department of Physical Education and Sport Sciences, University of Thessaly, Karies, 42100 Trikala, Greece, Tel: +302431047005; Fax: +302431047042; E-mail: bgerom@pe.uth.gr

Citation: Gerodimos V (2015) Whole Body Vibration: A Revolutionary Mode of Exercise or A Trend? Int J Phys Ther Rehab 1: 109. doi: http://dx.doi. org/10.15344/2455-7498/2015/109

Copyright: (C) 2015 Gerodimos. This is an open-access article distributed under the terms of the Creative Commons Attribution License, which permits unrestricted use, distribution, and reproduction in any medium, provided the original author and source are credited. 
Citation: Gerodimos V (2015) Whole Body Vibration: A Revolutionary Mode of Exercise or A Trend? Int J Phys Ther Rehab 1: 109. doi: http://dx.doi. org/10.15344/2455-7498/2015/109

Page 2 of 3

have also reported inconsistent findings. Thus, chronic WBV studies have been shown to either increaseor to have no-effect on neuromuscular performance. More specifically, WBV training studies using either vertical simultaneous or side-to-side vibration reported increase in flexibility, strength and power, as well as in walking ability, balance and mobility especially in untrained and elderly individuals [25-27]. On the other hand, reports have documented non-significant improvements in neuromuscular performance, using side-to-side or vertical simultaneous vibration, in young or physically active individuals or athletes [28-29]. For this reason, several studies have focused on the efficacy of combined vibration and neuromuscular/ cardiovascular training programs to improve various indices of health and overall fitness in different populations. There is evidence that a combination of vibration and strength, flexibility and aerobic training is more effective than vibration training alone in counteracting the detrimental effects of a sedentary lifestyle on musculoskeletal and cardiovascular systems [3,30-31].

\section{Whole body vibration and rehabilitation}

Several studies in the literature have focused on the beneficial effects of WBV in patients who suffer from neurological, musculoskeletal and metabolic diseases $[2,12]$. In detail, there is evidence that chronic WBV exposure may decrease spasticity and pain levels in different clinical populations, while the results concerning strength, balance, mobility, gait and motor impairment are ambivalent [2,12]. More specifically, it appears that balance, mobility, strength, walking ability and motor impairment either increase or remain unchanged following WBV training interventions [2,12]. Therefore, WBV may be used, in some cases, as a better alternative to traditional modes of exercise for the improvement of functional capacity and quality of life, especially in clinical populations.

Taking all the above into consideration, whole-body vibration seems to bea less fatiguing and a less time-consuming mode of exercise for prevention of injury and for improving neuromuscular performance, particularly in less fit individuals. Whole-body vibration exercise takes place indoors and requires less volitional input that may increase adherence to exercise training program. Thus, untrained individuals or clinical populations, due to their inactive life-style and the relatively low level of physical fitness, appear as good candidates to benefit from a WBV training. However, it seems that WBV per se is not an adequate training stimulus for young or physically active individuals. Consequently, for young or active individuals is recommended WBV exercise in conjunction with traditional modes of exercise such as stretching, resistance and aerobic exercises.

\section{References}

1. Cardinale $\mathrm{M}$, Wakeling $\mathrm{J}$ (2005) Whole body vibration exercise: are vibrations good for you? Br J Sports Med 39: 585-589.

2. Chanou K, Gerodimos V, Karatrantou K, Jamurtas A (2012) Whole-body vibration and rehabilitation of chronic diseases: a review of the literature. $J$ Sports Sci Med 11: 187-200.

3. Cochrane DJ (2012) Is vibration exercise a useful addition to a weight management program? Scand J Med Sci Sports 22: 705-713

4. Albasini A, Krause M, Rembitzki I (2010) Using whole body vibration in physical therapy and sport. Edinburgh: Churchill Livingstone.

5. Da Silva-Grigoletto ME, Vaamonde DM, Castillo E, Poblador MS, GarcíaManso JM, et al. (2009) Acute and cumulative effects of different times of recovery from whole body vibration exposure on muscle performance. $\mathrm{J}$ Strength Cond Res 23: 2073-2082.
6. Bazett-Jones DM, Finch HW, Dugan EL (2008) Comparing the effects of various whole-body vibration accelerations on counter-movement jump performance. J Sports Sci Med 7: 144-150.

7. Crewther B, Cronin J, Keogh J (2004) Gravitational forces and whole body vibration: implications for prescription of vibratory stimulation. Phys Ther Sport 5: 37-43.

8. Luo J, McNamara B, Moran K (2005) The use of vibration training to enhance muscle strength and power. Sports Med 35: 23-41.

9. Abercromby AF, Amonette WE, Layne CS, McFarlin BK, Hinman MR, et al. (2007) Variation in neuromuscular responses during acute whole-body vibration exercise. Med Sci Sports Exerc 39: 1642-1650.

10. Gojanovic B, Henchoz Y (2012) Whole-body vibration training: metabolic cost of synchronous, side-alternating or no vibrations. J Sports Sci 30 $1397-1403$

11. Cardinale M, Leiper J, Erskine J, Milroy M, Bell S (2006) The acute effects of different whole body vibration amplitudes on the endocrine system of young healthy men: a preliminary study. Clin Physiol Funct Imaging 26: 380-384

12. Wunderer K, Schabrun SM, Chipchase LS (2008) The effect of whole-body vibration in common neurological conditions - a systematic review. Phys Ther Rev 13: 434-442.

13. Cochrane DJ, Stannard SR (2005) Acute whole body vibration training increases vertical jump and flexibility performance in elite female field hockey players.Br J Sports Med 39: 860-865

14. Cormie P, Deane RS, Triplett NT, McBride JM (2006) Acute effects of whole-body vibration on muscle activity, strength, and power. J Strength Cond Res 20: 257-261.

15. Torvinen S, Kannu P, Sievänen H, Järvinen TA, Pasanen M, et al. (2002) Effect of a vibration exposure on muscular performance and body balance. Randomized cross-over study. Clin Physiol Funct Imaging 22: 145-152.

16. Gerodimos V, Zafeiridis A, Karatrantou K, Vasilopoulou T, Chanou K, et al (2010) The acute effects of different whole-body vibration amplitudes and frequencies on flexibility and vertical jumping performance. J Sci Med Sport 13: $438-443$.

17. Rittweger J, Beller G, Felsenberg D (2000) Acute physiological effects of exhaustive whole-body vibration exercise in man. Clin Physiol 20: 134-142.

18. Bullock N, Martin DT, Ross A, Rosemond CD, Jordan MJ, et al. (2008) Acute effect of whole-body vibration on sprint and jumping performance in elite skeleton athletes. J Strength Cond Res 22: 1371-1374.

19. Rittweger J, Mutschelknauss M, Felsenberg D (2003) Acute changes in neuromuscular excitability after exhaustive whole body vibration exercise as compared to exhaustion by squatting exercise. Clin Physiol Funct Imaging 23: 81-86

20. Issurin VB (2005) Vibrations and their applications in sport. A review. J Sports Med Phys Fitness 45: 324-336.

21. Broadbent S, Rousseau JJ, Thorp RM, Choate SL, Jackson FS, et al (2010) Vibration therapy reduces plasma IL6 and muscle soreness after downhill running. Br J Sports Med 44: 888-894.

22. Goto K, Takamatsu K (2005) Hormone and lipolytic responses to whole body vibration in young men. Jpn J Physiol 55: 279-284.

23. Di Loreto C, Ranchelli A, Lucidi P, Murdolo G, Parlanti N, et al. (2004) Effects of whole-body vibration exercise on the endocrine system of healthy men. J Endocrinol Invest 27: 323-327.

24. Theodorou AA, Gerodimos V, Karatrantou K, Paschalis V, Chanou K, et al. (2015) Acute and Chronic Whole-Body Vibration Exercise does not Induce Health-Promoting Effects on The Blood Profile. J Hum Kinet 46: 107-118.

25. Bautmans I, Van Hees E, Lemper JC, Mets T (2005) The feasibility of Whole Body Vibration in institutionalised elderly persons and its influence on muscle performance, balance and mobility: a randomised controlled trial [ISRCTN62535013]. BMC Geriatr 5: 17.

26. Gerodimos V, Zafeiridis A, Chanou K, Karatrantou K, Dipla K (2015) Wholebody vibration training in middle-aged females: improving muscle flexibility and the power of lower limbs. Sport Sci Health 11: 287-294. 
Citation: Gerodimos V (2015) Whole Body Vibration: A Revolutionary Mode of Exercise or A Trend? Int J Phys Ther Rehab 1: 109. doi: http://dx.doi. org/10.15344/2455-7498/2015/109

Page 3 of 3

27. Russo CR, Lauretani F, Bandinelli S, Bartali B, Cavazzini C, et al. (2003) High-frequency vibration training increases muscle power in postmenopausal women. Arch Phys Med Rehabil 84: 1854-1857.

28. Karatrantou K, Gerodimos V, Dipla K, Zafeiridis A (2013) Whole-body vibration training improves flexibility, strength profile of knee flexors, and hamstrings-to-quadriceps strength ratio in females. J Sci Med Sport 16: 477-481.

29. Delecluse C, Roelants M, Diels R, Koninckx E, Verschueren S (2005) Effects of whole body vibration training on muscle strength and sprint performance in sprint-trained athletes. Int J Sports Med 26: 662-668.

30. Emerenziani GP, Meucci M, Gallotta MC, Buzzachera CF, Guidetti L, et al. (2014) Whole body vibration: unsupervised training or combined with a supervised multi-purpose exercise for fitness? J Sports Sci 32: 1033-1041.

31. Feland JB, Hawks M, Hopkins JT, Hunter I, Johnson AW, et al. (2010) Whole body vibration as an adjunct to static stretching. Int J Sports Med 31: 584-589. 